ÉGYPTE

monde arabe

\section{Égypte/Monde arabe}

$6 \mid 2003$

D'une intifâda l'autre. La Palestine au quotidien

\title{
« La rue politique »
}

Sawt al-Umma, 8 avril 2002

\section{Muhammad al-Bâz}

\section{(2) OpenEdition}

\section{Journals}

Édition électronique

URL : https://journals.openedition.org/ema/944

DOI : $10.4000 /$ ema.944

ISSN : 2090-7273

Éditeur

CEDEJ - Centre d'études et de documentation économiques juridiques et sociales

Édition imprimée

Date de publication : 31 décembre 2003

Pagination : 151-154

ISBN : 2-87027-993-0

ISSN : 1110-5097

Référence électronique

Muhammad al-Bâz, « "La rue politique » », Égypte/Monde arabe [En ligne], 6 | 2003, mis en ligne le 08 juillet 2008, consulté le 07 juillet 2022. URL : http://journals.openedition.org/ema/944 ; DOI : https:// doi.org/10.4000/ema.944

Ce document a été généré automatiquement le 7 juillet 2022.

Tous droits réservés 


\title{
«La rue politique »
}

\author{
Sawt al-Umma, 8 avril 2002
}

\section{Muhammad al-Bâz}

1 Dix jours sans sommeil pour les Palestiniens, dix jours sans répit pour les Égyptiens qui ont envahi les rues. Oubliant les difficultés financières qui l'étouffent, révolté contre le massacre des Palestiniens et les tentatives de Sharon cherchant à les exterminer, à anéantir leur identité et à tuer leur symbole en la personne de Yâsir cArafât [Arafat], le peuple égyptien a envahi les rues. Abandonnant les paroles pacifiques, et les tremblements dus à sa maladie, 'Arafât s'est transformé en lion rugissant refusant de se rendre et prêt à mourir pour sa cause.

2 Mettant de côté leur insouciance habituelle et plutôt que de rester absorbés par la recherche de leur gagne-pain, les Égyptiens ont choisi de se faire hautement entendre des dirigeants arabes pour défendre, non seulement la cause palestinienne, mais aussi leur propre existence. Les slogans brandis dans les différentes manifestations, du genre « Demain viendra notre tour », ne sont en fait que l'expression de la crainte qu'un autre pays arabe ne soit la prochaine cible des attaques.

3 Les manifestations n'ont pas fait que révéler la nature du peuple égyptien, son patriotisme et sa conscience politique ; elles ont aussi démasqué la faiblesse des partis, de certains secteurs étatiques et de certains groupes islamistes, notamment l'association des Frères musulmans, et démontré l'incapacité des syndicats à organiser une manifestation ou une marche. Le jour où les journalistes ont voulu protester contre les événements et exprimer leur colère, plus de cent d'entre eux entourés de la police anti-émeute, se sont vu contraints à ne pas dépasser les marches du syndicat.

4 Ayant perdu toute confiance dans les organisations politiques et sociales, lycéens, étudiants et fonctionnaires ont spontanément envahi les rues. Leur ardeur et leur enthousiasme ont amené le chef de l'État à sortir les en féliciter lui-même. Devant l'impact produit par ces manifestations, la presse nationale étatique qui, pourtant, affecte une grande réserve, a dû publier les nouvelles et les photos, voire louer les manifestations et les glorifier.

5 Durant ces dernières années, peut-être depuis 1991, année des manifestations étudiantes contre la première guerre d'Irak, ce sont les groupes islamistes qui 
organisaient les manifestations, ralliaient les étudiants des différentes facultés et lançaient des slogans en mettant en avant le caractère islamique de la cause palestinienne. Pour eux, la Palestine est islamique : Khaybar, khaybar yâ yâhûd, jaysh Muhamad sawfa yaûd (Khaybar, Khaybar, ô Juifs, l'armée de Muhamad est de retour)...bil-rûh, bi-l-damm nafdîka yâ islâm...Isrâ'îl akbar am Allah? Allah akbar Isrâ'îl aczam am amrîca ? Allâh aczam...y â yahûdî yâ khasîs, damm al-muslim mish rakhîs ...

6 Tout au long des années quatre-vingt-dix, les groupes islamistes s'attribuaient le droit exclusif de manifester pour la cause palestinienne et, à maintes reprises, les étudiants qui ont tenté de participer à ces manifestations et d'acclamer l'arabité de la Palestine, ont été attaqués par leurs collègues islamistes. Ces groupes concevaient, et continuent de concevoir, ce conflit comme un conflit religieux dans lequel l'islam est visé, indépendamment de tout ce qui est dit à propos de l'arabité de Jérusalem.

Dans les manifestations qui ont débuté samedi dernier et qui se poursuivent jusqu'à présent, les islamistes ne sont plus qu'un groupe parmi d'autres, mais ils adoptent le même mécanisme et les mêmes slogans que les Frères musulmans - «Le Coran entre deux épées » - et les versets relatifs au jihâd - wa aiddû lahum mâ istatactum min quwwa wa min ribât al-khayl - La seule nouveauté a été de remplacer le slogan lancé par les Égyptiens au lendemain de la défaite du 5 juin 1967 appelant à la guerre par un appel au jihâd, ce qui correspond à leur état d'esprit et à leur désir d'ouvrir la porte du jihâd : yâ hukûmat al-bilâd iftahî bâb al-jihâd.

Dans une manifestation qui a eu lieu l'an dernier, proclamant haut et fort l'idée du jihâd, les jeunes islamistes se sont trouvés dans une mauvaise passe. S'emparant d'un haut-parleur, un officier des Forces de sécurité leur a demandé ce qu'ils voulaient. Ce à quoi ils ont répondu à l'unanimité : la guerre, la guerre... L'officier a alors demandé que tous ceux qui voulaient combattre se mettent de côté, précisant que les autorités les aideraient à partir pour la guerre. À la surprise de tous, aucun étudiant ne s'est avancé. Il ne s'agissait donc que de slogans et de paroles dans le vide! Les acclamations des groupes islamistes prétendant que la participation aux manifestations les rapprochait de Dieu et que le boycott des produits israéliens et américains était un moyen d'obtenir la grâce de Dieu, ont failli donner lieu à une dissension à l'Université du Caire. Dans une marche pacifique organisée par la faculté de Communication où les étudiantes criaient haut et fort les slogans, un groupe d'étudiants relevant des courants islamistes a intercepté la marche et essayé de faire taire les filles sous prétexte que la voix des femmes est cawra et que si elles voulaient participer aux manifestations, elles devaient garder le silence.

9 Il en a été autrement des manifestations soutenues par des professeurs d'université de différentes tendances politiques. Ces derniers ont participé à l'organisation et à la préparation des manifestations et leur ont assuré une certaine protection. Ainsi, les professeurs de l'Université du Caire ont-ils pris contact avec les instances de sécurité pour leur demander d'assurer la protection d'une manifestation prévue pour le dimanche. Selon l'accord conclu, les étudiants étaient autorisés à sortir de l'enceinte de l'Université mais sans dépasser la statue Nahdat misr située en face de l'ambassade d'Israël, et sans tenter d'atteindre l'ambassade. Cependant, les forces de l'ordre n'ont pas tenu leur engagement et lorsque les étudiants ont tenté de franchir l'enceinte universitaire, grenades lacrymogènes, jet d'eau et autres, ont été utilisés pour les disperser. Les cris des émeutiers se sont alors élevés contre les forces de l'ordre et contre le gouvernement. Les professeurs qui participaient à la manifestation ont essayé 
de calmer les étudiants, de les convaincre de ne pas attaquer le gouvernement et de centrer leurs slogans sur la cause palestinienne. N'ayant pas réussi à maîtriser la situation et réalisant que la manifestation avait dérapé, beaucoup de professeurs se sont retirés.

$\mathrm{Au}$ départ, les manifestations estudiantines ont bénéficié de l'appui officiel. Le président de l'Université de Janûb al-Wâdî a même reçu un appel d'un haut responsable s'étonnant que son université soit la seule où il n'y ait pas eu de manifestations. Le rôle joué par les responsables n'était donc pas moins important que celui du shaykh Ahmad Yâsîn qui a apporté son soutien aux groupes islamistes et était invité à prononcer une allocution dans chaque manifestation organisée par les étudiants dans les universités du Caire, d'Alexandrie et de Zagazig.

11 Cependant, les manifestations n'ont pas été que positives. Des dérapages ont eu lieu ; non seulement les vitrines, mais également les appareils téléphoniques des MacDonalds et Kentuckys situés à proximité de l'Université du Caire ont été démolis. Signe que les manifestations pouvaient vite se transformer en violence anarchique. Peut-être est-ce la raison qui a poussé les forces de l'ordre à interdire les manifestations hors de l'université: la crainte que les étudiants appelant à la vengeance n'attaquent l'ambassade d'Israël était grande.

12 Les étudiants ont cherché à attiser les manifestations en diffusant des nouvelles relatives aux attaques répétées des Israéliens. Certains ont même prétendu que cArafât avait été assassiné. En réaction à ces rumeurs, les forces de l'ordre ont alors essayé de disperser les manifestants ou du moins de les calmer en annonçant la décision du gouvernement d'expulser l'ambassadeur d'Israël ou de rompre les relations diplomatiques avec ce pays. Devant le grand enthousiasme des étudiants à l'annonce de cette nouvelle, les forces de l'ordre ont pris prétexte des slogans hostiles au gouvernement pour attaquer les étudiants.

13 Il était prévisible que toutes les universités égyptiennes organiseraient des manifestations, mais ce qui l'était moins, c'est que l'université privée du 6-Octobre agisse. En fait, ce sont les étudiants palestiniens de cette université qui en ont pris l'initiative, appuyés par tous les autres étudiants arabes et plus particulièrement les Libanais et les Koweïtiens. Cette manifestation a eu lieu sans incidents, sous la protection des forces de sécurité.

14 La mobilisation des écoliers et des lycéens a été nettement plus facile. Ils ont participé aux manifestations organisées par les universités. Celle des élèves de l'école secondaire al-saîdiyya à Gizeh a été sévèrement réprimée. Voir une cinquantaine de garçons et de filles accompagnés de leurs professeurs défiler dans les rues des villes égyptiennes en acclamant la Palestine, est devenu un spectacle courant ces derniers jours. Même s'ils n'avaient pas leurs propres mots d'ordre. Parmi les slogans amusants qu'ils criaient : $y \hat{a}$ shârûn yâ majnûn battal siyâsa wa bî̀ laymûn ("Sharon, tu es fou, arrête de faire de la politique et vends des citrons »).

15 Les élèves du primaire ont fait plus que ce qu'ont fait les partis politiques à l'exception du Parti nassérien. Les manifestants, qui défilaient en brandissant les photos de Nâsir, se sont fait violemment agresser par les forces de l'ordre. Alors que les autres partis ont organisé rencontres et colloques, le PND a, comme d'habitude, gardé le silence et s'est contenté d'observer les évènements en simple spectateur. 
Ce qui s'est passé dans l'ordre des avocats montre bien la faiblesse et la fragilité du Syndicat des journalistes. Alors que les avocats se sont rassemblés nombreux devant leur syndicat pour manifester leur colère et proclamer devant les chaînes satellites arabes et les dirigeants arabes que la solution se trouvait dans les armes et non dans l'initiative saoudienne, al-hall bi-l-bunduqiyya mish bi mubâdara sacudiyya, seul un petit nombre de journalistes a prononcé des discours déclamatoires devant un conseil syndical qui n'a même pas réussi à se protéger et à défendre la cause des journalistes. Certains journalistes se sont alors retirés du Syndicat, à leur plus grand regret.

17 Les artistes étaient mieux organisés. Rassemblés devant le ministère des Affaires étrangères avec un grand nombre d'écrivains qui s'étaient ralliés à eux, ils ont affiché leur position et exigé la rupture des relations non seulement avec Israël, mais également avec les États-Unis qu'ils estiment être râs al-afâa (la tête de la vipère) et le moteur du mal dans la région. Un trait amusant dans cette affaire : le Syndicat des cinéastes est toujours à la recherche de quelqu'un qui maîtrise la langue hébraïque pour écrire le mot "assassins » et l'afficher avec les photos de Sharon, de Barak et de Netanyahou, à l'entrée de leur syndicat, qui se trouve rue cAdlî, juste en face de la synagogue.

18 La rue égyptienne s'est montrée capable d'agir, de s'exprimer et de manifester son indignation à sa manière, sans rien attendre des partis politiques, ni des groupes islamistes, ni des O.N.G. Ce qui obligera tout un chacun à refaire ses calculs.

\section{INDEX}

Mots-clés : Palestine 